\title{
Identifying the Complexity of Diagnosing Bipolar Disorder: A Focused Ethnography
}

\author{
Post-Print
}

Abstract: Purpose: To identify and describe the complexity of diagnosing bipolar disorder, including the diagnostic process and patient experiences of being newly diagnosed with bipolar disorder.

Design: A mixed-methods focused ethnography was conducted, grounded in a post-positivist foundation. Methods: Medical records $(n=100)$ of patients whose diagnosis had been switched to bipolar disorder were examined. Six weeks post-hospitalization, ten outpatients with the diagnosis of bipolar disorder underwent an in-depth interview.

Findings: Four diagnostic processes were identified during the retrospective record review. Two patterns and five themes were identified from the interviews. The first pattern, living with undiagnosed bipolar disorder, demonstrated common experiences of distinguishing impulsive moods and behavior, suffering life challenges, and seeking relief. The second pattern, acclimating to a new diagnosis of bipolar disorder, demonstrated participants' ways of understanding the diagnosis and reconciling the diagnosis. Patterns in the interviews corroborated data from the record review.

Conclusions: The rendering of an appropriate diagnosis is key. Many participants' lives were significantly improved when diagnosis was made, and treatment recommendations for bipolar disorder (BPD) were initiated. These findings offer clinicians and researchers new ways to think about the complexity of the diagnosis of BPD including contrasting decision-making outcomes along a screening, diagnosis, and treatment continuum, as well as using the diagnostic event to instigate meaningful life change in the patient.

Deposit Statement: This is an Accepted Manuscript of an article published by Taylor \& Francis in 'Issues in Mental Health Nursing' on 2019-06-27, available online:

https://www.tandfonline.com/10.1080/01612840.2019.1615584.

Publisher's version: https://www.tandfonline.com/doi/full/10.1080/01612840.2019.1615584

Citation: Stiles, Brandie M., et al. "Identifying the Complexity of Diagnosing Bipolar Disorder: A Focused Ethnography." Issues in Mental Health Nursing, vol. 40, no. 9, 2019, pp. 812-818., doi:10.1080/01612840.2019.1615584. 
Bipolar disorder (BPD) is a progressive psychiatric illness that affects 5.5 million individuals in the United States (American Psychiatric Association [APA], 2013; National Alliance for Mental Illness, 2018). Correct diagnosis and treatment of BPD, which promotes positive mental health outcomes, has global appeal given that BPD is one of the leading causes of disability worldwide (Strassnig et al., 2018). This condition is often difficult to recognize and subsequently treat. BPD is frequently misdiagnosed as major depression disorder because patients report depressive episodes more frequently than manic episodes, and they tend to seek office visits during the depressive episodes (Cardoso de Almeda \& Phillips, 2013). According to the current APA Guidelines (Silverman et al., 2015), patients screening positive for BPD should be started on a mood stabilizer or an antipsychotic medication. In cases of acute mania, the recommendation is to start the patient on both types of medication to help achieve mood stability more quickly.

Correctly diagnosing BPD, according to APA guidelines, is imperative. If major depression disorder with its markedly different treatment protocols is diagnosed instead, incorrect treatment may worsen bipolar symptoms (Baldessarini et al., 2013). Moreover, it is well established that patients who have BPD and are diagnosed with major depression disorder and treated with antidepressants are at an increased risk for serious consequences: poorer outcomes in social functioning, more annual hospitalizations, and more lifetime suicide attempts (Altamura et al., 2015; Oyffe, Shwizer, \& Stolovy, 2015). One in five patients with BPD complete suicide (Lemaire \& Graham, 2011).

Several major factors contribute to the complexity of diagnosing BPD and may lead to misdiagnosis. Patients' failure to report mania symptoms is one of the greatest barriers to correct diagnosis (Hirschfeld, Lewis, \& Vornik, 2003). From a patient's perspective, hypomania, a less extreme form of mania, may be enjoyable and productive in the beginning of the episode, so patients are less likely to report symptoms (Lim, Nathan, O'Brien-Malone, \& Williams, 2004). Moreover, embarrassment related to social stigma surrounding BPD may influence reporting of symptoms (Owen, Gooding, Dempsey, \& Jones, 2015). Patients with BPD reportedly feel more stigmatized than people with other forms of mental illness (Bassirnia et al., 2015). Also, some patients may not accept a BPD diagnosis, believing their symptoms point to a different psychiatric disorder (Poole, Smith, \& Simpson, 2015). These are major reasons why only $20 \%$ of patients with BPD receive the correct diagnosis within the first year of seeking treatment (Grunze et al., 2018). Nasrallah (2015) estimated that the time it takes a patient to get a correct BPD diagnosis and start on the correct treatment is 5-10 years. 
Table 1. Diagnostic processes revealed during analysis of medical records review data ( $n 1 / 4100)$.

\begin{tabular}{|c|c|c|c|c|c|c|}
\hline $\begin{array}{l}\text { Diagnostic } \\
\text { process }\end{array}$ & $\begin{array}{l}\text { Pre-hospital } \\
\text { diagnosis } \\
\text { and } \\
\text { treatment }\end{array}$ & $\begin{array}{l}\text { Screening } \\
\text { result }\end{array}$ & $\begin{array}{l}\text { Diagnosis } \\
\text { made }\end{array}$ & $\begin{array}{l}\text { Treatment } \\
\text { prescribed }\end{array}$ & $\begin{array}{l}\text { Percentage } \\
\text { of patients in } \\
\text { chart review }\end{array}$ & Comment \\
\hline 1 & $\begin{array}{l}\text { Major } \\
\text { depression } \\
\text { disorder and } \\
\text { on appropriate } \\
\text { medication for } \\
\text { this disorder }\end{array}$ & $\begin{array}{l}\text { Screened } \\
\text { positive for } \\
\text { BPD }\end{array}$ & BPD & Treated for BPD & $51 \%$ & $\begin{array}{l}\text { Best } \\
\text { management } \\
\text { outcome } \\
\text { according to APA } \\
\text { recommendations }\end{array}$ \\
\hline 2 & $\begin{array}{l}\text { Major } \\
\text { depression } \\
\text { disorder and } \\
\text { on appropriate } \\
\text { medication for } \\
\text { this disorder }\end{array}$ & $\begin{array}{l}\text { Screened } \\
\text { negative } \\
\text { for BPD }\end{array}$ & BPD & Treated for BPD & $37 \%$ & $\begin{array}{l}\text { Screening tool not } \\
\text { sufficient and } \\
\text { clinical history } \\
\text { and provider } \\
\text { judgement } \\
\text { needed to } \\
\text { establish the } \\
\text { diagnosis }\end{array}$ \\
\hline 3 & $\begin{array}{l}\text { Major } \\
\text { depression } \\
\text { disorder and } \\
\text { on medication } \\
\text { not for this } \\
\text { disorder, but } \\
\text { medication for } \\
\text { BPD }\end{array}$ & $\begin{array}{l}\text { Screened } \\
\text { positive for } \\
\text { BPD }\end{array}$ & BPD & $\begin{array}{l}\text { Continued } \\
\text { same } \\
\text { treatment } \\
\text { after switched } \\
\text { to BPD }\end{array}$ & $8 \%$ & $\begin{array}{l}\text { The condition not } \\
\text { initially labeled as } \\
\text { BPD, delaying } \\
\text { diagnosis }\end{array}$ \\
\hline 4 & $\begin{array}{l}\text { Major } \\
\text { depression } \\
\text { disorder and } \\
\text { on appropriate } \\
\text { medication for } \\
\text { this disorder }\end{array}$ & $\begin{array}{l}\text { Screened } \\
\text { positive for } \\
\text { BPD }\end{array}$ & BPD & $\begin{array}{l}\text { Not treated for } \\
\text { BPD }\end{array}$ & $4 \%$ & $\begin{array}{l}\text { Lack of treatment } \\
\text { for BPD not ideal } \\
\text { and may } \\
\text { reflect quality of } \\
\text { care } \\
\text { issues, rea- } \\
\text { son unknown }\end{array}$ \\
\hline
\end{tabular}

Note. BPD: bipolar disorder.

The misunderstanding and the stigma surrounding BPD are barriers to seeking care and obtaining the correct diagnosis. For example, major problems remain: (a) the suffering that occurs without correct BPD diagnosis and treatment and (b) the idea that patients may not want the BPD diagnosis label or the stigma attached. Moreover, a recent integrative review on the appropriate diagnosis and treatment of BPD revealed a paucity of research about patients' experiences throughout the diagnostic process, and the extent to which patients accept the BPD diagnosis (Stiles, Fish, Vandermause and Malik, 2018). Therefore, the purpose of the current study was to identify and describe the complexity of diagnosing BPD, including the diagnostic process and patient experiences of being newly diagnosed with BPD. The information from patient medical records about decisionmaking practices related to the diagnostic process (screening results and choosing the diagnosis and treatment) was interpreted along with information about patients' perspectives and experiences through the question, "What is it like to be newly diagnosed with BPD?" The current study is distinctive because it focuses on the diagnostic process of a unique population in mental health care, one 
characterized by specific behaviors and challenges. Furthermore, it examines the event of rendering a diagnosis of BPD in the context of a recent hospitalization, providing a practical focus for understanding. The premise of this paper is that the clinical evidence examined in-depth will help unravel the complexity of BPD and aid in the more appropriate diagnosis and treatment of BPD, to reduce the occurrence of misdiagnosis.

Methodology and methods

A focused ethnography was chosen for this study because it concentrated on a particular aspect of a subculture, patients that have been newly diagnosed with BPD. This variation from classic ethnography (Spradley, 1979) may also be called microethnography (Polit \& Beck, 2008) and often uses participant observation, interviews, and examination of relevant documents (Fetterman, 2010). Nurse researchers have used focused ethnography to study particular clinical populations in this way (Bialoskurski, Cox, \& Hayes, 1999; Gerrish, Naisby, \& Ismail, 2013; Green, McSweeney, Ainley, \& Bryant, 2009; Hales, de Vries, \& Coombs, 2016) and have added their clinical expertise to the perspectives of members of the population (Roper \& Shapira, 2000). Methods used in this study included a retrospective record review and indepth semi-structured interviews. The retrospective medical record review provided evidence about the diagnostic process, from screening results to diagnosis and to treatment of BPD. The in-depth face to face interviews, completed approximately 6 weeks post-hospital discharge, demonstrated the shared experiences across transcripts of patients newly diagnosed with BPD. The study was approved by the Institutional Review Board, protocol number 895151-2.

Setting, sample, and data collection for the retrospective medical record review

Existing inpatient medical records at a psychiatric hospital in the Midwest United States were analyzed. Inclusion criteria for records reviewed were: (a) patients 18-65 years of age, (b) a diagnosis of major depression disorder upon hospital admission switched to BPD by discharge, (c) screening for BPD, and (d) complete data. De-identified data included demographics, admitting diagnosis, urine drug screen results, psychiatric intake admission information, psychiatric evaluation by a health care provider, medication administration record, and discharge summary.

Setting, sample, and data collection for the in-depth interviews

Ten participants recruited from an inpatient unit at a freestanding psychiatric hospital were interviewed in a private room at one of six psychiatrists' offices in a city in the Midwest United States. Inclusion criteria were: (a) participants 18-65 years of age, (b) newly diagnosed with BPD during an inpatient psychiatric admission 29-42 days prior, and (c) written informed consent to be interviewed. An interview guide, based on the 
Ethnographic Interview (Spradley, 1979), was used. Queries included asking the patient to compare their life before hospital admission to after, and how having a new diagnosis of BPD had impacted their life. Interviews lasted 45-90 min and were voice recorded, de-identified, and transcribed verbatim. A reflective journal was maintained, and memoing was incorporated to record reflections and insights. Prominent materials from a fieldwork journal were integrated into the data analysis process.

\section{Data analysis}

Data from each analytical method were integrated in the mixed-methods findings (Creswell, 2009). Medical records were de-identified by the hospital data manager, coded, and exported to SPSS. The analysis of records data was accomplished using frequencies and percentages. All interview and field note data were read by the primary and secondary investigators and coded to reflect units of meaning, patterns, themes, and descriptions of experiences related to the research question. Spradley's (1979) four levels of data analysis, including domain, taxonomic, componential, and cultural themes were used.

\section{Results}

The record review revealed four distinctly different diagnostic processes (see Table 1). Regardless of diagnostic process, $96 \%$ of the patients obtained the correct pharmacological treatment for BPD. In this review, $51 \%$ of patients screened positive for $B P D$, were diagnosed with BPD, and were switched from an antidepressant to a mood stabilizer (Diagnostic process 1; see Table 1). This is the best management outcome according to current APA recommendations.

Next, $37 \%$ of patients screened negative for BPD, and their diagnosis and treatment were still switched from major depression disorder to BPD (Diagnostic process 2; see Table 1). This implies that the screening tool is not sufficient for rendering a diagnosis and that the clinical history and provider judgment are needed to establish the diagnosis. In this review, $8 \%$ of patients had a pre-hospital diagnosis of major depression disorder and previously prescribed mood stabilizers, a usual treatment for BPD (Diagnostic process 3; see Table 1). This means that the condition was not initially labeled as BPD. Finally, $4 \%$ of patients screened positive for BPD but were not started on a mood stabilizer, for unknown reasons (Diagnostic process 4; see Table 1). This situation is not ideal and may reflect quality of care issues. Also, nearly half of the patients admitted to inpatient care had a positive urine drug screen (48\%) and $49 \%$ had a history of at least one suicide attempt.

Findings from interviews are presented in the form of interpretive patterns and themes with exemplars for illustration. In the pattern, living with undiagnosed BPD, participants demonstrated common experiences of distinguishing impulsive moods and behavior, suffering life challenges, and seeking relief. In the pattern, acclimating to a new 
diagnosis of BPD, participants exhibited ways of understanding the diagnosis and reconciling the diagnosis.

\section{Living with undiagnosed BPD}

The overarching pattern of living with undiagnosed BPD was based on the content of each participant's description of their lives before the diagnosis of BPD. For many, the symptoms of BPD started during the school age or adolescent years. All three of the following themes captured the common experiences that describe the distinctive period of preBPD diagnosis.

Distinguishing impulsive moods and behavior

Throughout the interviews, participants repeatedly reported moods and behaviors that they felt were not normal. Many of the moods and behaviors were consistent with the state of mania, including uncontrollable emotions and actions. Participants recalled specific time points in their lives when problems in their relationships and employment developed, when they felt out of control and guilty over the way they had treated their family members. Many of the participants were tearful, and one participant acknowledged that she should have gone for help sooner but was too embarrassed and ashamed.

\section{Suffering life challenges}

Life circumstances, for many, seemed more severe than for persons without BPD. Symptoms appeared over a lifetime and involved "repeated arguing," "a lot of relationship problems," "divorces," and "failed marriages." Life challenges varied from participant to participant; all participants remembered them as unmanageable aspects of their lives. Both the depression and manic symptoms created challenges for patients. For example, Stella (names are pseudonyms) recalled that her life challenges started during childhood:

So, you know, I was being truant - like truancy from school. And my parents were getting in trouble for that. I wasn't doing anything I was supposed to be doing, so I ended up in a residence facility ... 'Cause I did four years in prison and I was clean the whole time. I went for involuntary manslaughter.

This example of severe life challenges resulting from undiagnosed BPD demonstrates the extent to which patients can suffer.

Seeking relief 
Impulsive behavior and increased life challenges led to the next step in the progression of undiagnosed symptoms, that of seeking relief. Participants had sought many avenues to relieve symptoms, including use of illegal or controlled substances. Some went to numerous health care providers seeking any kind of diagnosis and treatment that would help.

Seeking relief through substance abuse was the most common remedy among the participants. Many of them had a substance addiction. Stella recalled:

But I wasn't paying attention to like the things I knew were wrong. I just was kinda—pushed 'em to the back and lettin' 'em go. And then you turn to drugs and you turn to other ways you know how to cope.

Sophie obtained controlled substances through her medical doctor in order to use the medication as an "escape." "Yeah. But again, I was lying about having it, you know, cause I wanted to get Xanax."

Some participants relayed a long history of self-harm that started in adolescence. For instance, Avery always kept suicide in the back of his mind as a backup plan in case his moods never improved. "And a lot of the stuff that l've done was based on the contingency that I could just commit suicide and I wouldn't be in a particular situation and I wouldn't get stuck. You know?" Similarly, Bill stated:

Ah, the cutting was mostly angry. Like it wasn't a depressed, don't want to be here. Like it was always-like you can see the scars—some of 'em—on my arm. I would just get so mad. They're up there. And then even like the arguments with the exgirlfriend at the timenow, you know, current girlfriend. And l'd just-l'd get so mad l'd just need to hurt something. So l'd just, you know, take a knife to my arm.

In these instances, suicide and self-harm are perceived as remedies, ways of seeking relief.

What was most striking about participants' stories were accounts of repeated hardships they endured. When symptoms of BPD are listed in a Diagnostic and Statistical Manual of Mental Disorders (DSM-5), the list does not convey the severity of the effect on a person's life. Extant literature focuses extensively on suicide being the most severe consequence of having undiagnosed or misdiagnosed BPD (Meyer et al., 2011; Tondo, Vazquez, \& Baldessarini, 2010), yet other forms of suffering in the lives of these patients are under-explored. Eight out of 10 participants used self-harm as a last resort.

Acclimating to a new diagnosis of BPD

Participants were asked to describe how receiving a new diagnosis of BPD impacted their lives, as compared to life before the hospitalization. Each participant had experienced a reduction of BPD symptoms after starting on the correct treatment. The 
themes below summarize the difficulties with social and self-stigma, and the degree of acceptance expressed.

\section{Understanding the diagnosis}

BPD is a highly stigmatizing disorder and has led to patients not reporting or underreporting their symptoms due to fear of getting diagnosed (Meyer et al., 2011). Although participants were newly diagnosed with BPD, many of them did not understand the illness. During many of the interviews, participants asked for information such as what BPD is, how it is diagnosed, and how mania symptoms appear. In addition, many of the participants described how they felt about people they knew who had BPD. As explained by Bonnington and Rose (2014) and supported by the results of this study, social stigma affects the way a person with BPD views the illness. Participants related, "you never know what to expect," "they are more crazy," and "people treat people differently if they know they have bipolar disorder."

Many of the participants described their own negative view of BPD and did not think they had BPD symptoms. Olivia, who worked in the field of mental health, acknowledged the stigma that even mental health providers may have working with patients with BPD: "As a (health care provider) myself, I know the stigma where if you tell someone you're depressed versus tell somebody you're bipolar, even as a (health care provider), you're viewed differently." None of the participants described the condition favorably. These data support a continued stigma toward patients with BPD, despite mental health awareness ads, campaigns, and community support groups intended to reduce stigma. The social stigma of BPD continues.

\section{Reconciling the diagnosis}

All the participants had varying degrees of accepting the diagnosis. While no participant completely disagreed with the diagnosis, some reported mixed feelings and attributed their symptoms to illicit drug use rather than BPD. Acknowledging the diagnosis provided an explanation for the symptoms and behaviors that resulted in distress in their lives. At the beginning of the interview, Sophie blamed drug use as the reason for the diagnosis; however, toward the end of the interview and after further thoughtful conversation, she was more accepting of the diagnosis as appropriate. She reported:

That'd be the only thing that l'd say. And I feel like the test, too, of taking it. Like I was on drugs, so I don't know if they took that into account or not. Like I - I wrote, "on drugs." You know? Cause, I mean-I think stuff like that should be taken into account. But other than that, I guess that's all.

In contrast, several participants agreed that BPD fit their symptoms and explained years of impulsive moods and behavior. When asked if he agreed with the diagnosis, Sterling reported 'I agree one hundred percent." Maggie reported relief knowing that her 
symptoms could be explained: "I guess it would be considered a relief knowing that there was a name to it".

It is important to note that participants needed to have some basic level of acceptance of the BPD diagnosis to respond to the study flyers and participate in the study. Whether or not patients accepted the diagnosis wholeheartedly, they recognized the value of receiving it. Even if participants did not agree with the diagnosis, all participants acknowledged that the new medication for BPD was working to relieve symptoms. These are all components of reconciling the diagnosis.

\section{Discussion}

The problem of misdiagnosis of BPD was underscored when we noted that the overall percent of those switched from major depression disorder to a diagnosis of BPD during inpatient visits in 1 year at our hospital was $16.9 \%$. Although this estimate is comparable to that noted in the literature (Nasrallah, 2015), the number misdiagnosed was deemed by the hospital to be too high and required further study.

The mixed-methods approach used in this study yielded rich data, and the data identified in the interviews corroborated that from the records review. These data reinforced the importance of focusing on the holistic well-being of the patient, including an exploration of the patients' life activities and social interactions, not just the diagnosis.

A considerable number of patients $(37 \%)$ did not recognize or did not report impulsive moods and behaviors during screening with a standardized screening tool; based on negative screening alone, these patients might not have received the right diagnosis and treatment. However, in these cases, clinical judgment was used based on the history, presentation, and life activities to diagnose and treat BPD, which may have reduced long-term suffering. Receiving a BPD diagnosis in the hospital allows the patient to understand the diagnosis and a chance to reconcile the diagnosis, themes identified in the interview data.

The degree of illicit drug use and suicidality found in the records review is similar to that reported in the literature (Balanza-Martınez, Crespo-Facorro, Gonzalez-Pinto, \& Vieta, 2015). These behaviors can be interpreted as seeking relief before diagnosis and treatment, as a response to suffering related to BPD. Suffering is likely severe, given the extremes to which people develop these unsuccessful coping mechanisms (Vazquez et al., 2011). The inpatient diagnostic visit is a place to help patients adjust to a BPD diagnosis. Receiving a new diagnosis sets BPD patients on a different trajectory, one that may prevent illicit drug use and suicide.

A delayed diagnosis was noted in one diagnostic process, in which $8 \%$ of patients before hospitalization had a diagnosis of major depression disorder, not BPD, but had been incorrectly placed on mood stabilizers. Then in the hospital, these participants screened positive for BPD, were diagnosed with BPD, and were kept on the same mood stabilizers as previously prescribed. This delayed diagnosis did not help the patient 
understand or reconcile a BPD diagnosis. The advantages and disadvantages of naming the diagnosis need to be further explored.

The majority of patients $(51 \%)$ went through a process of standard diagnosis and treatment of BPD preceded by screening (APA, 2013). Accordingly, they were able to recognize their symptoms and were willing to report them on the screening tool. The history, presentation, life activities, and screening outcomes all pointed to BPD, providing them an opportunity to understand and reconcile the diagnosis.

Strengths and limitations

The study was strengthened by a mixed-methods focused ethnographic design that allowed for a multi-perspectival understanding of common experiences in a particular clinical population with unique vulnerabilities. Yet, the generalizability of our research findings is limited. Extant research does not include experiences of a patient newly diagnosed with BPD. Given that the number of veterans diagnosed with BPD is almost double that of the general population (Ilgen et al., 2010), recruiting veterans for future studies is essential. This study should be replicated in different urban and rural geographical areas.

Implications

When the diagnosis and treatment of BPD are correct, we assume the patient is able to reconcile the diagnosis, is more likely to take medications appropriately and make lifestyle changes compatible with recommendations. The results from the retrospective record review indicate that BPD may be initially diagnosed as major depression disorder, and that those ultimately diagnosed with BPD have a strong history of substance use and suicide attempts. Thus, the challenges associated with diagnosis and treatment remain, even in hospitals specializing in psychiatric care.

Some of the symptoms of BPD may be hidden from oneself or from health care providers. Thus, providers are obligated to seek and consider ambiguous or incompletely expressed accounts by patients in making a BPD diagnosis. The treatment for BPD, pharmacological and behavioral/lifestyle change, needs to be offered even if the diagnosis may be shunned.

The rendering of the diagnosis of BPD is a key event that may be a turning point for those who have previously been misdiagnosed, a unique opportunity to emphasize the possibility for a transformative process that can shift the trajectory of the disease. Helping newly diagnosed persons to understand the diagnosis is equally important and may assist in patients' reconciling the diagnosis, coming to terms with the stigma, and making lifestyle modifications needed to manage their condition. 


\section{Conclusions}

The major findings in this focused ethnography supported and expanded previously existing knowledge about the complexity of diagnosing BPD. The use of a focused ethnography was adept in acquiring new information on these participants who have been newly diagnosed with BPD. Moreover, a deeper understanding of the social and cultural context was gained within this population. This study adds the unique aspect of relating diagnostic processes with ethnographic experiences found in actual present-day clinical practice.

Extensive research is still needed based on the fact that many patients newly diagnosed do not understand BPD, none rated the diagnosis as favorable, and all had varying degrees of acceptance. On a more positive note, we found that participants recognized the value of receiving a diagnosis and acknowledged that the new medication was working to relieve symptoms. The rendering of an appropriate diagnosis is key. Many participants' lives were significantly improved when diagnosis was made and treatment recommendations for BPD were initiated. These findings offer clinicians and researchers new ways to think about the complexity of the diagnosis of BPD including contrasting decision-making outcomes along a screening, diagnosis, and treatment continuum, as well as using the diagnostic event to instigate meaningful life change in the patient.

We are part of a major movement internationally to reduce misdiagnosis. Many models have been published on misdiagnosis in general. Yet, we focus specifically on the urgent need for correct diagnosis in patients with BPD, so that patients can make lifestyle modifications needed to manage their condition.

Clinical resources

https://www.nami.org

http://ibpf.org

Disclosure statement

No conflicts of interest exist.

Funding

This study was funded from a grant from the Jonas Nursing and Veterans Health Care Scholarship Foundation. 


\section{ORCID}

Roxanne Vandermausehttp://orcid.org/0000-0002-0560-5450

\section{References}

Altamura, A. C., Buoli, M., Caldiroli, A., Caron, L., Cumerlato Melter, C., Dobrea, C., ... Zanelli Quarantini, F. (2015). Misdiagnosis, duration of untreated illness (DUI) and outcome in bipolar patients with psychotic symptoms: A naturalistic study. Journal of Affective Disorders, 182, 70-75. doi:10.1016/j.jad.2015.04.024

American Psychiatric Association. (2013). Diagnostic and statistical manual of mental disorders: DSM-5. Washington, DC: Author.

Balanza-Martınez, V., Crespo-Facorro, B., Gonzalez-Pinto, A., \& Vieta, E. (2015). Bipolar disorder comorbid with alcohol use disorder: Focus on neurocognitive correlates. Frontiers in Physiology, 108(6), 1-9. doi:10.3389/fphys.2015.00108

Baldessarini, R. J., Faedda, G. L., Offidani, E., Vazquez, G. H., Marangoni, C., Serra, G., \& Tondo, L. (2013). Antidepressant-associated mood-switching and transition from unipolar major depression to bipolar disorder: A review. Journal of Affective Disorders, 148(1), 129-135. doi:10.1016/j.jad.2012.10.033

Bassirnia, A., Briggs, J., Kopeykina, I., Mednick, A., Yaseen, Z., \& Galynker, I. (2015). Relationship between personality traits and perceived internalized stigma in bipolar patients and their treatment partners. Psychiatry Research, 230(2), 436-440. doi:10.1016/j.psychres.2015.09.033

Bialoskurski, M., Cox, C. L., \& Hayes, J. A. (1999). The nature of attachment in a neonatal intensive care unit. The Journal of Perinatal \& Neonatal Nursing, 13(1), 6677.

Bonnington, O., \& Rose, D. (2014). Exploring stigmatisation among people diagnosed with either bipolar disorder or borderline personality disorder: A critical realist analysis. Social Science \& Medicine (1982), 123, 7-17. doi:10.1016/j.socscimed.2014.10.048

Cardoso de Almeda, J. R., \& Phillips, M. L. (2013). Distinguishing between unipolar depression and bipolar depression: Current and future clinical and neuroimaging perspectives. Biological Psychiatry, 73, 111-118. doi:10.1016/j.biopsych.2012.06.010

Creswell, J. W. (2009). Research design: Qualitative, quantitative, and mixed methods approaches. Los Angeles, CA: Sage.

Fetterman, D. M. (Ed.) (2010). Ethnography: Step-by-step. (Vol. 17). Thousand Oaks, CA: Sage.

Gerrish, K., Naisby, A., \& Ismail, M. (2013). Experiences of the diagnosis and management of tuberculosis: A focused ethnography of Somali patients and 
healthcare professionals in the UK. Journal of Advanced Nursing, 69(10), 2285-2294. doi:10.1111/jan.12112

Green, A. L., McSweeney, J., Ainley, K., \& Bryant, J. (2009). Comparing parents' and children's views of children's quality of life after heart transplant. Journal for Specialists in Pediatric Nursing, 14(1), 49-58. doi:10.1111/j.1744-6155.2008.00173.x Grunze, H., Vieta, E., Goodwin, G. M., Bowden, C., Licht, R. W., Azorin, J.-M., ... Kasper, S, ... \& Members of the WFSBP Task Force on Bipolar Affective Disorders Working on This Topic. (2018). The World Federation of Societies of Biological Psychiatry (WFSBP) guidelines for the biological treatment of bipolar disorders: Acute and long-term treatment of mixed states in bipolar disorder. The World Journal of Biological Psychiatry, 19(1), 2-58. doi:10.1080/ 15622975.2017.1384850

Hales, C., de Vries, K., \& Coombs, M. (2016). Managing social awkwardness when caring for morbidly obese patients in intensive care: A focused ethnography. International Journal of Nursing Studies, 58, 82-89.

doi:10.1016/j.ijnurstu.2016.03.016

Hirschfeld, R. M., Lewis, L., \& Vornik, L. A. (2003). Perceptions and impact of bipolar disorder: How far have we really come? Results of the National Depressive and Manic-Depressive Association 2000 survey of individuals with bipolar disorder. The Journal of Clinical Psychiatry, 64(2), 161-174. doi:10.4088/JCP.v64n0209

Ilgen, M. A., Bohnert, A. S., Ignacio, R. V., McCarthy, J. F., Valenstein, M. M., Kim, M., \& Blow, F. C. (2010). Psychiatric diagnosis and risk of suicide in veterans. Archives of General Psychiatry, 67(11), 1152-1158. doi:10.1001/archgenpsychiatry.2010.129

Lemaire, C. M., \& Graham, D. P. (2011). Factors associated with suicidal ideations in OEF/OIF veterans. Journal of Affective Disorders, 130(1-2), 231-238. doi:10.1016/j.jad.2010.10.021

Lim, L., Nathan, P., O'Brien-Malone, A., \& Williams, S. (2004). A qualitative approach to identifying psychosocial issues faced by bipolar patients. Journal of Nervous and Mental Disease, 192(12), 810-817. doi:10.1097/01.nmd.0000146734.39501.57

Meyer, T. D., Bernhard, B., Born, C., Fuhr, K., Gerber, S., Schaerer, L., ... Bauer, M. (2011). The Hypomania Checklist-32 and the Mood Disorder Questionnaire as screening tools-Going beyond samples of purely mood-disordered patients. Journal of Affective Disorders, 128(3), 291-298. doi:10.1016/j.jad.2010.07.003

Nasrallah, H. A. (2015). Consequences of misdiagnosis: Inaccurate treatment and poor patient outcomes in bipolar disorder. The Journal of Clinical Psychiatry, 76(10), e1328. doi:10.4088/JCP.14016tx2C

National Alliance of Mental Illness. (2018). Bipolar Disorders. Retrieved from https://www.nami.org/Blogs/NAMI-Blog/March-2018/Understanding-theSpectrum-ofBipolar-Disorder.

Owen, R., Gooding, P., Dempsey, R., \& Jones, S. (2015). A qualitative investigation into the relationships between social factors and suicidal thoughts and acts experienced by people with a bipolar disorder diagnosis. Journal of Affective Disorders, 176, 133140. doi: 10.1016/j.jad.2015.02.002 
Oyffe, I., Shwizer, R., \& Stolovy, T. (2015). The association between diagnosis, treatment delay, and outcome among patients with bipolar disorders. Psychiatric Quarterly, 86(1), 95-105. doi:10.1007/ s11126-014-9316-4

Polit, D. F., \& Beck, C. T. (2008). Nursing research: Generating and assessing evidence for nursing practice. Philadelphia, PA: Lippincott Williams \& Wilkins.

Poole, R., Smith, D., \& Simpson, S. (2015). Patients' perspectives of the feasibility, acceptability and impact of a group-based psychoeducation programme for bipolar disorder: A qualitative analysis. BMC Psychiatry, 15, 1-16. doi:10.1186/s12888-0150556-0

Roper, J. M., \& Shapira, J. (2000). Ethnography in nursing research. Thousand Oaks, CA: Sage.

Silverman, J. J., Galanter, M., Jackson-Triche, M., Jacobs, D. G., Lomax, J. W., Riba, M. B., ... Yager, J. (2015). The American Psychiatric Association practice guidelines for the psychiatric evaluation of adults. Virginia: American Psychiatric Publishing.

Stiles, B. M., Fish, A. F., Vandermause, R., \& Malik, A. M. (2018). The compelling and persistent problem of bipolar disorder disguised as major depression disorder: An integrative review. Journal of American Psychiatric Nurses Association. 24(5), 415425. doi: $10.1177 / 1078390318784360$

Strassnig, M., Kotov, R., Fochtmann, L., Kalin, M., Bromet, E. J., \& Harvey, P. D. (2018). Associations of independent living and labor force participation with impairment indicators in schizophrenia and bipolar disorder at 20-year follow-up. Schizophrenia Research, 197, 150-155. doi:10.1016/j.schres.2018.02.009

Spradley, J. P. (1979). The ethnographic interview. New York, NY: Holt, Rinehart and Winston.

Tondo, L., Vazquez, G., \& Baldessarini, R. J. (2010). Mania associated with antidepressant treatment: Comprehensive meta-analytic review. Acta Psychiatrica Scandinavica, 121(6), 404-414. doi:10.1111/j.16000447.2009.01514.x

Vazquez, G. H., Kapczinski, F., Magalhaes, P. V., Cordoba, R., Jaramillo, C. L., Rosa, A. R., ... Tohen, M. (2011). Stigma and functioning in patients with bipolar disorder. Journal of Affective Disorders, 130, 323-327.

doi:10.1016/j.jad.2010.10.012 